\title{
A Robust Constraint on the Temperature and Height of the Extratropical Tropopause
}

\author{
DAVID W. J. THOMPSON \\ Department of Atmospheric Science, Colorado State University, Fort Collins, Colorado \\ PAULO CEPPI \\ Grantham Institute for Climate Change and the Environment, Imperial College London, London, United Kingdom \\ YING LI \\ Department of Atmospheric Science, Colorado State University, Fort Collins, Colorado
}

(Manuscript received 25 May 2018, in final form 22 October 2018)

\begin{abstract}
In a recent study, the authors hypothesize that the Clausius-Clapeyron relation provides a strong constraint on the temperature of the extratropical tropopause and hence the depth of mixing by extratropical eddies. The hypothesis is a generalization of the fixed-anvil temperature hypothesis to the global atmospheric circulation. It posits that the depth of robust mixing by extratropical eddies is limited by radiative cooling by water vapor-and hence saturation vapor pressures-in areas of sinking motion. The hypothesis implies that 1) radiative cooling by water vapor constrains the vertical structure and amplitude of extratropical dynamics and 2) the extratropical tropopause should remain at roughly the same temperature and lift under global warming. Here the authors test the hypothesis in numerical simulations run on an aquaplanet general circulation model (GCM) and a coupled atmosphere-ocean GCM (AOGCM). The extratropical cloud-top height, wave driving, and lapse-rate tropopause all shift upward but remain at roughly the same temperature when the aquaplanet GCM is forced by uniform surface warming of $+4 \mathrm{~K}$ and when the AOGCM is forced by RCP8.5 scenario emissions. "Locking" simulations run on the aquaplanet GCM further reveal that 1) holding the water vapor concentrations input into the radiation code fixed while increasing surface temperatures strongly constrains the rise in the extratropical tropopause, whereas 2) increasing the water vapor concentrations input into the radiation code while holding surface temperatures fixed leads to robust rises in the extratropical tropopause. Together, the results suggest that roughly invariant extratropical tropopause temperatures constitutes an additional "robust response" of the climate system to global warming.
\end{abstract}

\section{Introduction}

In a recent paper (Thompson et al. 2017), we hypothesized that clear-sky radiative cooling by water vapor plays a key role in governing the vertical extent of largescale mixing by extratropical eddies and thus of the depth of the extratropical troposphere. The hypothesis implies that the extratropical tropopause should stay at roughly the same temperature under global warming and thus provides an explanation for why the tropopause lifts under climate change (e.g., Mitchell and Ingram 1992; Santer et al. 2003; Lorenz and DeWeaver 2007; Singh and

Corresponding author: David W. J. Thompson, davet@atmos. colostate.edu
O'Gorman 2012). It also provides a physical explanation for why the climate feedbacks associated with high clouds in the tropics (Hartmann and Larson 2002; Zelinka and Hartmann 2010) also appear in association with clouds in the extratropics (e.g., Wetherald and Manabe 1988; Zelinka et al. 2012, 2013). In this paper, we test the hypothesis outlined in Thompson et al. (2017) in a series of numerical experiments. We begin with a brief review of the underlying physics.

\section{a. Physical basis}

At steady-state and on large (i.e., quasigeostrophic) scales, the transformed Eulerian mean (TEM) thermodynamic energy and zonal momentum equations can be expressed as 


$$
\begin{aligned}
f \bar{v}^{*} & =-\nabla \cdot F, \text { and } \\
-\bar{\omega}^{*} S & =\bar{Q},
\end{aligned}
$$

where the overbars denote zonal averages, $\bar{v}^{*}$ and $\bar{\omega}^{*}$ denote the zonal-mean residual circulation, $\nabla \cdot F$ denotes the divergence of the Eliassen-Palm (EP) flux (i.e., the "wave driving" of the large-scale circulation), and $\bar{Q}$ denotes diabatic processes. The EP flux divergence reflects the effects of wave drag on the zonalmean flow and-on quasigeostrophic (QG) scales-is equivalent to the eddy flux of potential vorticity: Regions of negative EP flux divergence (i.e., EP flux convergence) correspond to regions where the eddy flux of $\mathrm{PV}$ is equatorward and vice versa. By construction, the residual circulation corresponds to the component of the circulation that balances diabatic heating and thus approximates the diabatic (i.e., cross isentropic) mass flux. In regions where $\bar{\omega}^{*}$ is downward, there must be an imbalance between the zonal-mean diabatic heating (due to, say, condensational heating) and the zonal-mean diabatic cooling (due to, say, clear-sky radiative cooling). The residual zonal-mean diabatic cooling presumably derives from clear-sky radiative cooling.

The largest values of climatological-mean EP flux convergence (and thus equatorward eddy fluxes of PV) are located near the level of the midlatitude extratropical tropopause (Fig. 1; shading). The resulting westward torque is balanced by the Coriolis acceleration acting on poleward residual motion in the midlatitude upper troposphere [Eq. (1); Fig. 1; contours]. The poleward motion is, in turn, accompanied by downward motion in the mid-high latitude troposphere, and the downward motion at high latitudes is balanced by atmospheric radiative cooling [Eq. (2)].

The linkages between the EP flux divergence, the overturning residual circulation, and radiative cooling are generally viewed in the context of forcing by the wave drag: The larger the wave drag, the larger the amplitude of the residual circulation and thus of the dynamical heating and radiative cooling at high latitudes. From this perspective, the depth of the region of largest mixing in the extratropics - that is, the depth of the extratropical troposphere-is constrained by the dynamics of baroclinic instability (the "dynamical constraint"; Held 1982; Schneider 2004). The results in Thompson et al. (2017) suggest that the depth of vigorous mixing in the extratropics is also constrained by the vertical structure of clear-sky radiative cooling. The reasoning is as follows.

In sinking regions of the atmosphere, $Q$ [Eq. (2)] is dominated by water vapor radiative cooling (Simpson 1928; Manabe and Strickler 1964; Ingram 2010). The radiative cooling decreases sharply in the upper tropical troposphere at temperatures where the saturation vapor pressure-and hence the amount of water vapor available for radiant emissions-becomes very small in accordance with the Clausius-Clapeyron relation (Manabe and Strickler 1964; Hartmann et al. 2001). If clear-sky radiative cooling constrains the residual vertical motion $\bar{\omega}^{*}$, then from continuity, it must also constrain $\bar{v}^{*}$. And if clear-sky radiative cooling constrains $\bar{v}^{*}$, it must also constrain the amplitude of tropospheric wave breaking $-\nabla \cdot F$. From this perspective, the amplitude of tropospheric wave breaking and thus tropospheric diabatic mixing can only be as large as clear-sky radiative cooling will allow.

\section{b. Motivation}

The hypothesis outlined in Thompson et al. (2017) is a generalization of the physics of the fixed-anvil temperature (FAT) hypothesis to large-scale extratropical dynamics: The FAT hypothesis posits that the temperature of tropical anvil clouds is constrained by the amplitude of clear-sky radiative cooling by water vapor (Hartmann and Larson 2002); Thompson et al. (2017) argue that the same basic physics should also constrain the depth of large-scale diabatic mixing by extratropical eddies and thus of extratropical tropopause height. The generalization of the FAT hypothesis to the extratropical circulation has three primary implications: 1) It suggests that the depth of the extratropical troposphere is constrained by water vapor radiative cooling and thus the thermodynamic properties of water vapor; 2) it predicts that the extratropical tropopause should remain at roughly the same temperature under global warming and thus provides a physical explanation for the lifting of the extratropical circulation in climate-change simulations (e.g., Mitchell and Ingram 1992; Santer et al. 2003; Lorenz and DeWeaver 2007; Singh and O'Gorman 2012); and 3) it provides a physical explanation for the positive cloud feedbacks found at extratropical latitudes (e.g., Wetherald and Manabe 1988; Zelinka et al. 2012, 2013).

Here we test the generalization of the FAT hypothesis to the extratropical circulation in experiments run on an aquaplanet general circulation model (GCM) and in output from a coupled atmosphere-ocean GCM (AOGCM). Section 2 describes the numerical experiments; section 3 presents results based on the aquaplanet experiments; and section 4 presents results based on the coupled AOGCM. Conclusions are given in section 5.

\section{Numerical experiments and data}

\section{a. Aquaplanet experiments}

The aquaplanet experiments were run on the National Center for Atmospheric Research (NCAR) Community 


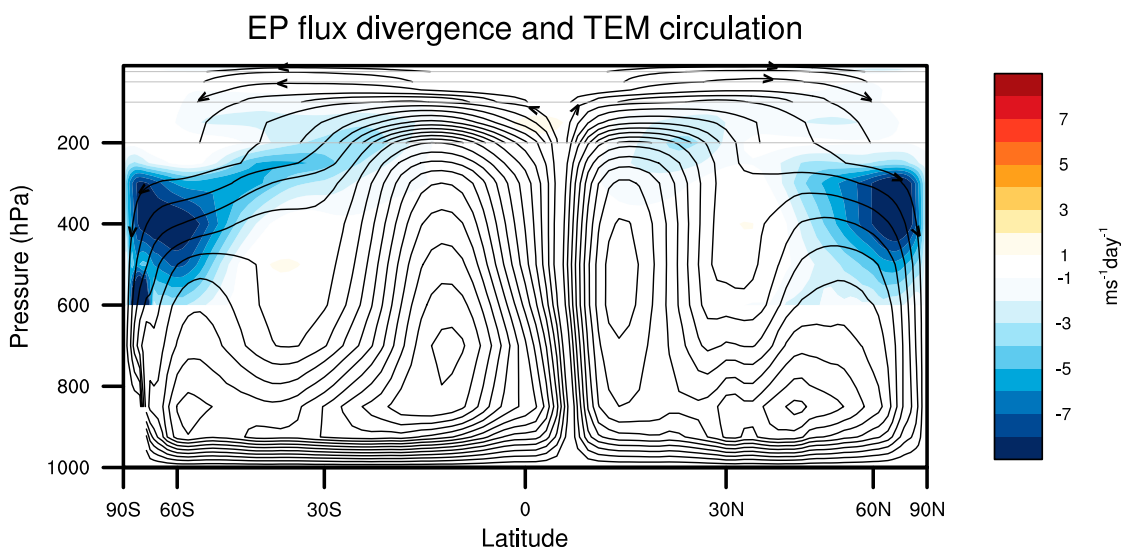

FIG. 1. The annual-mean, long-term mean (shading) EP flux divergence and (contours) Lagrangian-mean TEM circulation. Results are derived from ERA-Interim. The EP flux divergence is multiplied by the cosine of latitude. Contour intervals are at $8 \times 10^{-9} \mathrm{~kg} \mathrm{~s}^{-1}$ $(1000-200 \mathrm{hPa}), 4 \times 10^{-9} \mathrm{~kg} \mathrm{~s}^{-1}(200-100 \mathrm{hPa}), 2 \times 10^{-9} \mathrm{~kg} \mathrm{~s}^{-1}(100-50 \mathrm{hPa}), 1 \times 10^{-9} \mathrm{~kg} \mathrm{~s}^{-1}$ $(50-25 \mathrm{hPa})$, and $0.5 \times 10^{-9} \mathrm{~kg} \mathrm{~s}^{-1}(25-10 \mathrm{hPa})$.

Atmosphere Model, version 4 (CAM4). The version used here has a horizontal resolution of $1.9^{\circ}$ latitude $\times$ $2.5^{\circ}$ longitude, includes 26 vertical levels spanning the surface to $3.54 \mathrm{hPa}$, and explicitly calculates the shortwave and longwave radiative fluxes as per Collins et al. (2006). All experiments were run for five years (with the first year omitted to account for spinup) with specified sea surface temperatures (SSTs) under perpetual equinox conditions, and there is no land/sea geometry. Since the model is equatorially symmetric, the results are averaged over both hemispheres to increase the sample size in the analyses.

The effects of water vapor radiative cooling on the atmospheric circulation are explored in three primary sets of experiments run on the aquaplanet GCM. In set 1 , we test whether extratropical clouds, extratropical wave drag, and the extratropical tropopause rise and remain at roughly the same temperature in simulations where SSTs are raised uniformly by $4 \mathrm{~K}$. In sets 2 and 3 , we explore the role of water vapor radiative cooling on the circulation in two locking experiments: In set 2, SSTs are increased uniformly by $4 \mathrm{~K}$, but the water vapor concentrations input into the radiation code are held fixed at their control values; in set 3 , SSTs are held fixed at their control values, but the water vapor concentrations input into the radiation code are increased to the values derived from the warming experiment in set 1 . Experiments similar to the latter were performed in Harrop and Hartmann (2012), but were focused on tropical anvil clouds in a cloud-resolving model. Here we explore the effects of water vapor radiative cooling on the global-scale circulation in an aquaplanet GCM.
The details of the experiments are as follows:

- The $\mathrm{T}_{\text {ctl }}$ simulation was forced with the idealized, equatorially symmetric "Qobs" SST profile specified in Neale and Hoskins 2000 (the same configuration used in the CFMIP aquaplanet experiments).

- The $\mathrm{T}_{+4 \mathrm{~K}}$ simulation is identical to the $\mathrm{T}_{\mathrm{ctl}}$ simulation, except that SSTs are raised by $4 \mathrm{~K}$ relative to their control values.

- The $\mathrm{T}_{\mathrm{ctl}} \mathrm{W}_{\mathrm{ctl}}$ "locking" experiment was forced 1 ) with the SST profile from the $\mathrm{T}_{\mathrm{ctl}}$ experiment and 2) by overwriting the water vapor concentrations input into the radiation code at each radiative time step with resampled instantaneous values of the water vapor concentrations output from the $\mathrm{T}_{\mathrm{ctl}}$ experiment. The water vapor concentrations were resampled by shifting the values by one year so that the resampled water vapor values 1) are decoupled from the values calculated by the model and 2) have the same long-term mean, autocorrelation, and variance as the original values.

The effects of the locking methodology on the model atmosphere can be estimated by comparing the $\mathrm{T}_{\mathrm{ctl}} \mathrm{W}_{\mathrm{ctl}}$ and $\mathrm{T}_{\mathrm{ctl}}$ simulations. Decoupling the water vapor concentrations input into the radiation code from those calculated by the model means that the radiation scheme in the $\mathrm{T}_{\mathrm{ctl}} \mathrm{W}_{\mathrm{ctl}}$ simulation may "see" dry air in a moist updraft and vice versa. It also means that the water vapor concentrations input into the radiation code may exceed the saturation vapor pressure. In practice, the locking methodology leads to a weak cooling of the polar lower stratosphere but otherwise does not notably influence mean atmospheric temperatures (not shown). 
- The $\mathrm{T}_{+4 \mathrm{~K}} \mathrm{~W}_{\mathrm{ctl}}$ and $\mathrm{T}_{\mathrm{ctl}} \mathrm{W}_{+4 \mathrm{~K}}$ locking experiments are run in an analogous manner to the $\mathrm{T}_{\mathrm{ctl}} \mathrm{W}_{\mathrm{ctl}}$ experiment. In the $\mathrm{T}_{+4 \mathrm{~K}} \mathrm{~W}_{\mathrm{ctl}}$ experiment, SSTs are set to their $\mathrm{T}_{+4 \mathrm{~K}}$ simulation values while the water vapor concentrations input into the radiation code are set to their (resampled) $\mathrm{T}_{\mathrm{ctl}}$ simulation values. In the $\mathrm{T}_{\mathrm{ctl}} \mathrm{W}_{+4 \mathrm{~K}}$ experiment, SSTs are set to their $\mathrm{T}_{\mathrm{ctl}}$ simulation values while the water vapor concentrations input into the radiation code are set to their (resampled) $\mathrm{T}_{+4 \mathrm{~K}}$ simulation values.

\section{b. AOGCM output}

The hypotheses are also explored in numerical output from L'Institut Pierre-Simon Laplace (IPSL) climate model (version IPSL-CM5A-LR; Dufresne et al. 2013). We use two runs that were conducted under the auspices of phase 5 of the Coupled Model Intercomparison Project (CMIP5): 1) years 1979-2005 from the "historical" run (i.e., the run forced with estimates of historical anthropogenic forcing) and 2) years 2070-99 from the representative concentration pathway (RCP) 8.5 scenario run (i.e., the run forced with the RCP8.5 future anthropogenic forcing). The differences between the two runs represent the circulation response to twenty-first century forcing. The IPSL model output is available on a $3.75^{\circ}$ latitude $\times 1.875^{\circ}$ longitude mesh and at 39 vertical levels. Details of the physics parameterizations used in the IPSL AOGCM are provided in Hourdin et al. (2006).

\section{c. Observations}

The observational analyses shown in Fig. 1 are derived the ECMWF interim reanalysis (ERA-Interim) output sampled at 6-hourly intervals (Dee et al. 2011).

\section{d. Analysis details}

The EP flux divergence and TEM circulation are calculated in spherical coordinates using the quasigeostrophic form of the equations (Edmon et al. 1980). Cloud-top pressure is defined as the level where cloud fraction decreases to 0.01 (note that this definition does not necessary link directly to the radiative emission temperature of the cloud). The lapse-rate tropopause is defined as the lowest level where the lapse rate decreases below $2 \mathrm{~K} \mathrm{~km}^{-1}$ and remains below $2 \mathrm{~K} \mathrm{~km}^{-1}$ within the overlying $2 \mathrm{~km}$ of the atmosphere. The clearsky mass flux is defined as the flux required to balance the net diabatic cooling in clear-sky regions of the model and is calculated as

$$
\omega_{\text {clear }} \equiv-\frac{Q_{\text {clear }}}{S_{\text {clear }}},
$$

where $Q_{\text {clear }}$ and $S_{\text {clear }}$ are the radiative cooling and static stability in clear-sky regions, respectively (the atmospheric radiative cooling includes both shortwave and longwave components, but is dominated by the latter).

\section{Response of the extratropical tropopause to variations in surface temperature and atmospheric radiative cooling}

In this section, we explore the circulation response in three sets of experiments:

- Experiment set 1: The differences between the $T_{+4 K}$ and $\mathrm{T}_{\mathrm{ctl}}$ simulations.

The $\mathrm{T}_{+4 \mathrm{~K}}$ and $\mathrm{T}_{\mathrm{ctl}}$ simulations differ only in the SSTs prescribed as the lower boundary condition, thus the differences between the two allow us to test whether the extratropical tropopause (and thus mixing by large-scale extratropical variability) lifts globally in a manner predicted by the physics outlined in the introduction.

- Experiment sets 2 and 3: The differences between the $\mathrm{T}_{+4 \mathrm{~K}} \mathrm{~W}_{\mathrm{ctl}}$ and $\mathrm{T}_{\mathrm{ctl}} \mathrm{W}_{\mathrm{ctl}}$ simulations (set 2) and between the $\mathrm{T}_{\mathrm{ctl}} \mathrm{W}_{+4 \mathrm{~K}}$ and $\mathrm{T}_{\mathrm{ctl}} \mathrm{W}_{\mathrm{ctl}}$ simulations (set 3).

The $\mathrm{T}_{+4 \mathrm{~K}} \mathrm{~W}_{\mathrm{ctl}}$ and $\mathrm{T}_{\mathrm{ctl}} \mathrm{W}_{+4 \mathrm{~K}}$ locking experiments isolate the role of water vapor radiative cooling in the circulation response to surface warming in two different frameworks: One in which the water vapor concentrations input into the radiation code are held fixed while SSTs are increased $\left(\mathrm{T}_{+4 \mathrm{~K}} \mathrm{~W}_{\mathrm{ctl}}\right)$ and one in which the water vapor concentrations input into the radiation code are increased while SSTs are held fixed $\left(\mathrm{T}_{\mathrm{ctl}} \mathrm{W}_{+4 \mathrm{~K}}\right)$.

\section{a. Experiment set 1: The circulation response to surface warming in an aquaplanet GCM}

The left column in Fig. 2 shows the long-term mean, zonal-mean temperature (Fig. 2a) and specific humidity (Fig. 2c) from the $\mathrm{T}_{\mathrm{ctl}}$ simulation. Temperatures decrease with both latitude and altitude throughout the atmosphere from peak values in the tropical troposphere. The temperature minimum in the tropical stratosphere arises from the model BrewerDobson circulation, which-as expected because of the lack of orography in the model-is weaker than the observed. To first order, the latitude/height structure of the model specific humidity mirrors that of tropospheric temperatures, as mandated by the physics expressed in the Clausius-Clapeyron relation. The $220-\mathrm{K}$ isotherm and $0.5 \mathrm{~g} \mathrm{~kg}^{-1}$ isopleth are both located at $\sim 200 \mathrm{hPa}$ in the tropics and $\sim 400 \mathrm{hPa}$ at high latitudes (black contours).

The right column shows the differences in zonal-mean temperature and specific humidity between the $T_{+4 \mathrm{~K}}$ 

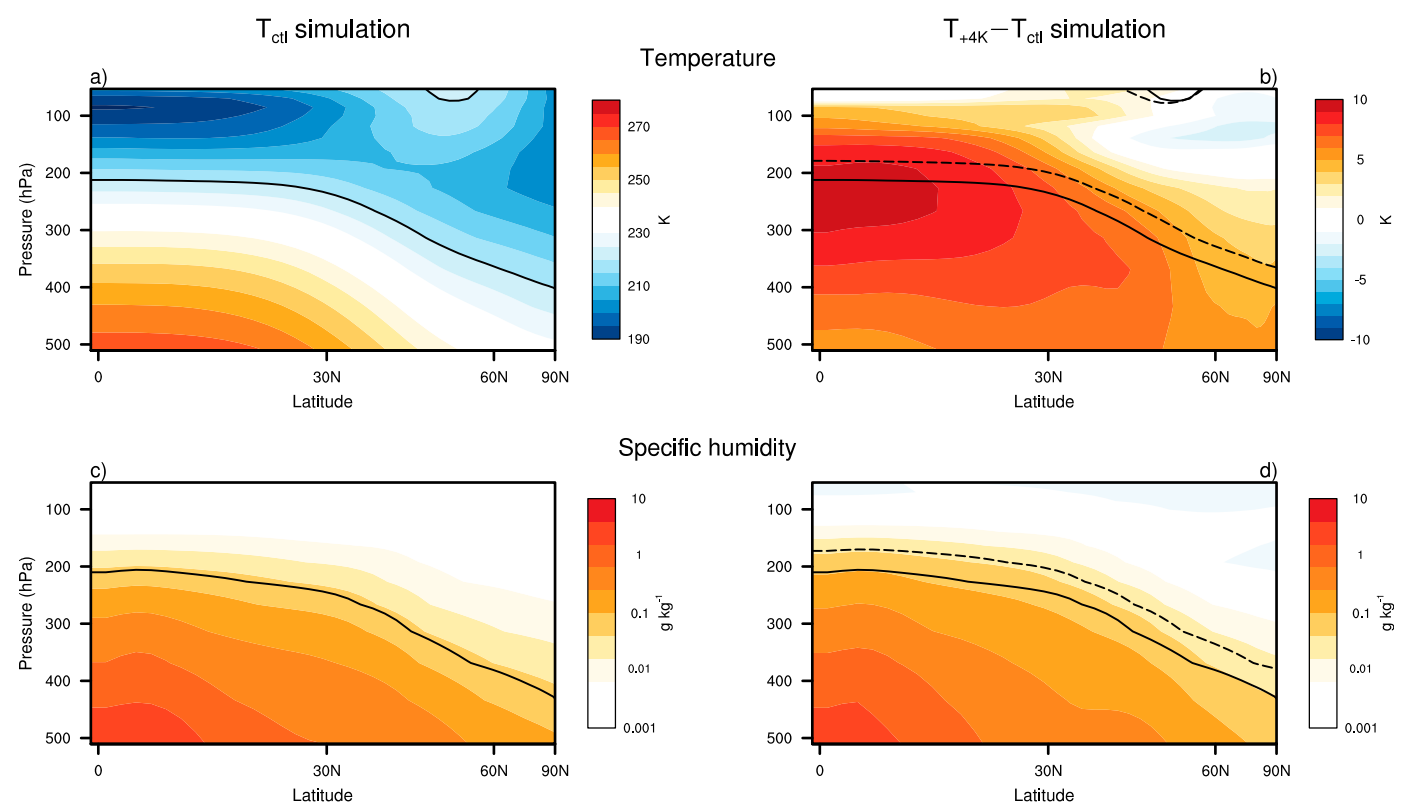

FIG. 2. The long-term mean (a),(b) zonal-mean temperature and (c),(d) specific humidity from the (left) $\mathrm{T}_{\text {ctl }}$ simulation and (right) differences between the $\mathrm{T}_{+4 \mathrm{~K}}$ and $\mathrm{T}_{\mathrm{ctl}}$ simulations. The black contours indicate the $220-\mathrm{K}$ isotherm in (a) and (b) and the $0.05 \mathrm{~g} \mathrm{~kg}^{-1}$ isopleth in (c) and (d) from the $\mathrm{T}_{\mathrm{ctl}}$ (solid) and $\mathrm{T}_{+4 \mathrm{~K}}$ (dashed) simulations. Note that specific humidity is plotted on a logarithmic scale since water vapor concentrations decrease exponentially with height. Light-blue shading in (d) indicates specific humidities between -0.001 and $0 \mathrm{~g} \mathrm{~kg}^{-1}$.

and $\mathrm{T}_{\mathrm{ctl}}$ simulations. As expected, raising SSTs by $4 \mathrm{~K}$ leads to widespread warming throughout the model troposphere and thus increases in specific humidity (shading). The warming peaks in the model tropical troposphere (Fig. 2b), where temperatures are closely fixed to the moist adiabatic lapse rate. The increases in surface temperature lead to a $\sim 30-50 \mathrm{hPa}$ lifting of the $220-\mathrm{K}$ isotherm and $0.5 \mathrm{~g} \mathrm{~kg}^{-1}$ isopleth (black contours).

Figure 3 shows corresponding results for clear-sky radiative cooling, the clear-sky mass flux divergence [recall that the clear-sky mass flux is defined in Eq. (3)], cloud fraction, and the EP flux divergence. The left column shows results from the $\mathrm{T}_{\mathrm{ctl}}$ simulation; the right column shows the differences between the $T_{+4 \mathrm{~K}}$ and $\mathrm{T}_{\text {ctl }}$ simulations. In the control simulation, the clear-sky cooling peaks in the tropical troposphere and decreases with both altitude and latitude (Fig. 3a), consistent with the meridional structure of specific humidity (Fig. 2c). The clear-sky mass fluxes likewise decrease rapidly with altitude-and thus the mass flux divergences have largest amplitude in the model upper troposphere (Fig. 3c). Cloud fraction decreases rapidly with height in the vicinity of the maximum in the clearsky mass flux divergence (shading in Fig. 3e), and cloud top extends to just below $100 \mathrm{hPa}$ in the tropics and $\sim 200 \mathrm{hPa}$ at high latitudes (the contour in Fig. 3e indicates the 0.07 cloud fraction isopleth). The EP flux convergence is largest-that is, the torque due to wave drag is largest westward-in the upper extratropical troposphere between $\sim 300$ and $500 \mathrm{hPa}$ (Fig. 3g).

Increasing SSTs by $4 \mathrm{~K}$ leads to widespread increases in clear-sky radiative cooling in the upper troposphere (Fig. 3b). The changes in clear-sky cooling rates are weaker in the midtroposphere than they are near the tropopause (Fig. 3b; shading), presumably because the water vapor absorption bands are already opaque to terrestrial radiation in the $T_{c t l}$ simulation. The increases in clear-sky radiative cooling lead to a lifting of the level where the clear-sky radiative cooling decreases rapidly with height (Fig. 3b; contours) and thus also in the levels of largest clear-sky mass flux divergences (Fig. 3d). Importantly, the upward shifts in the levels of vanishing clear-sky radiative cooling and largest mass flux divergences are not limited to the tropics but span the extratropics as well.

Consistent with the physics outlined in the introduction, raising SSTs by $4 \mathrm{~K}$ also leads to a lifting of the vertical profiles of cloud fraction and EP flux divergence. The vertical shifts in both fields are evidenced as vertical dipoles in the differences: Cloud fraction generally increases in the upper troposphere but decreases in the lower troposphere; the EP flux convergence shifts upward and poleward, consistent with both a lifting and poleward shift of the model storm 
$\mathrm{T}_{\mathrm{ctl}}$ simulation

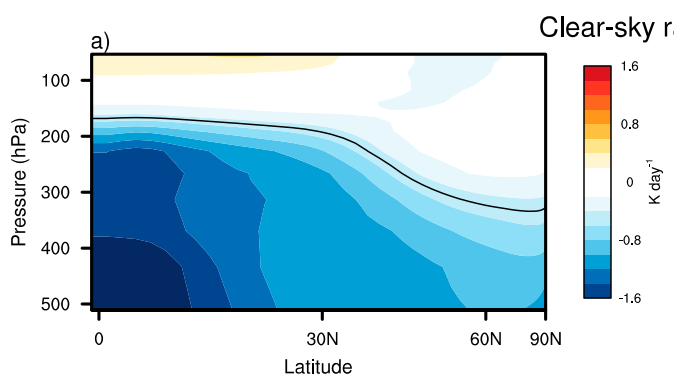

$T_{+4 K}-T_{c t l}$ simulation
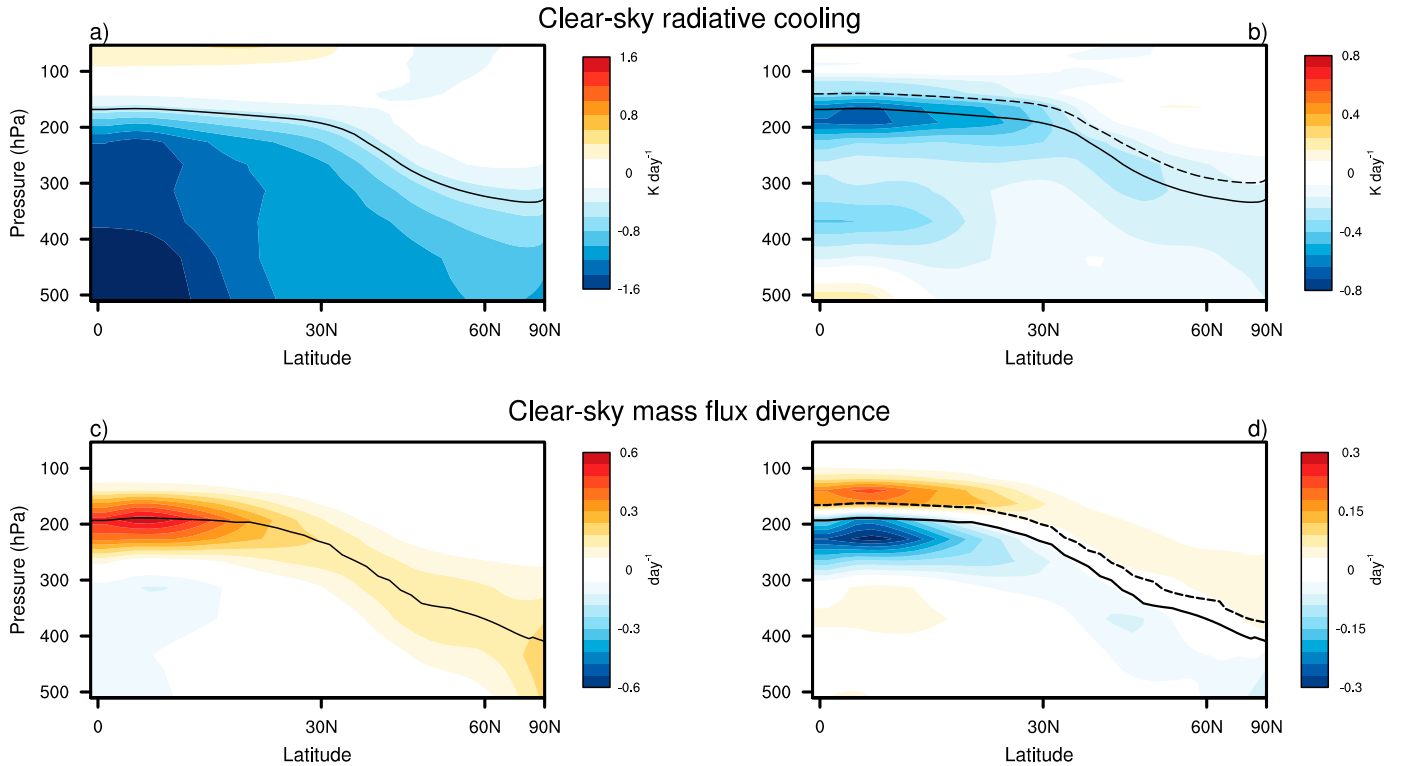

flux divergence
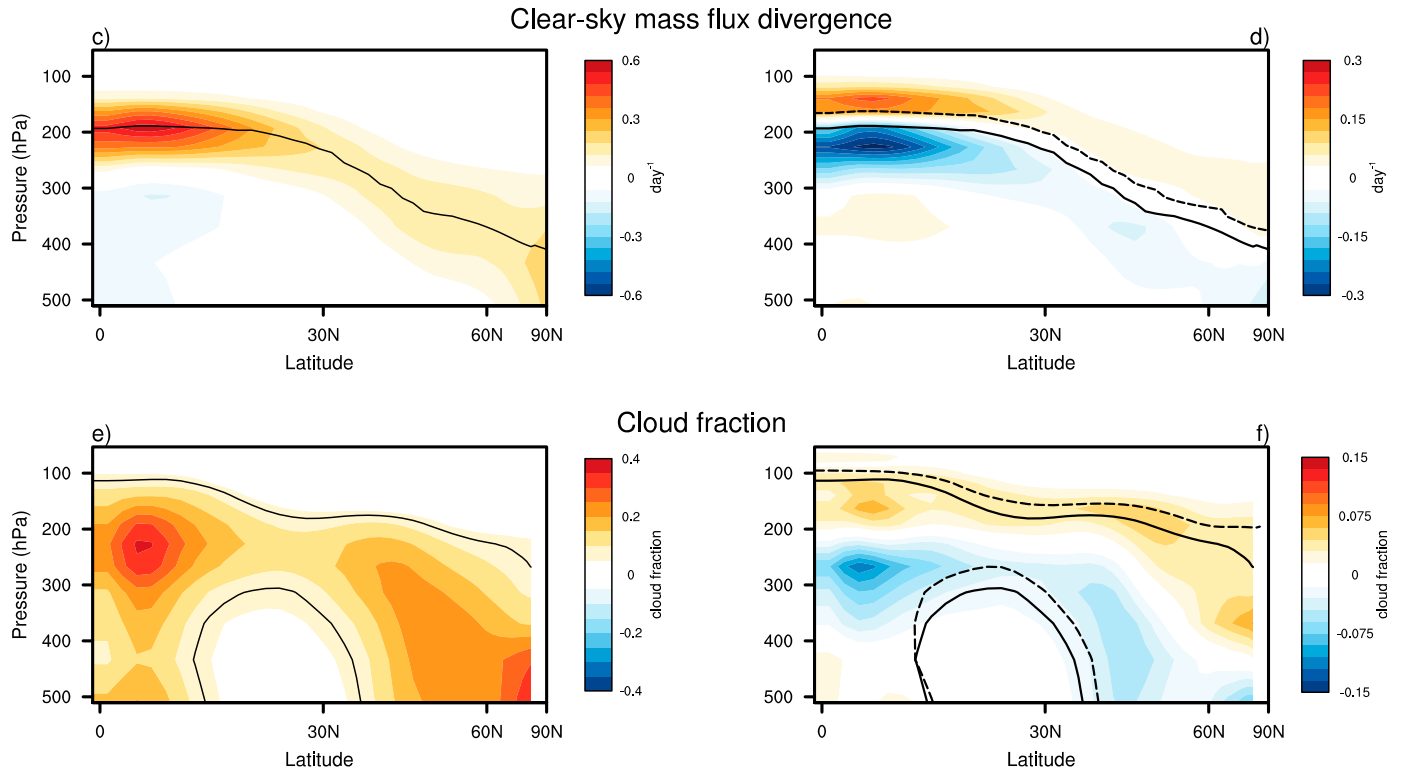

Cloud fraction
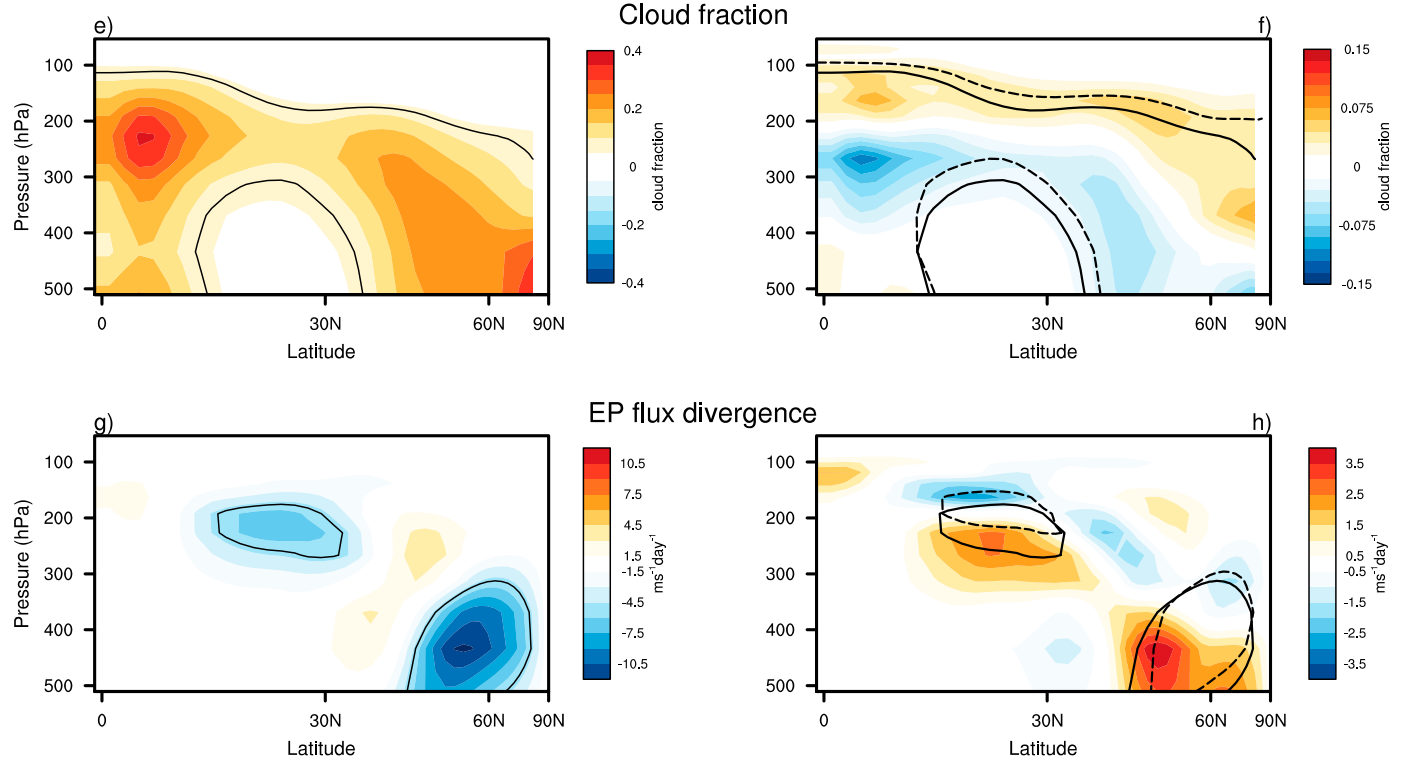

EP flux divergence

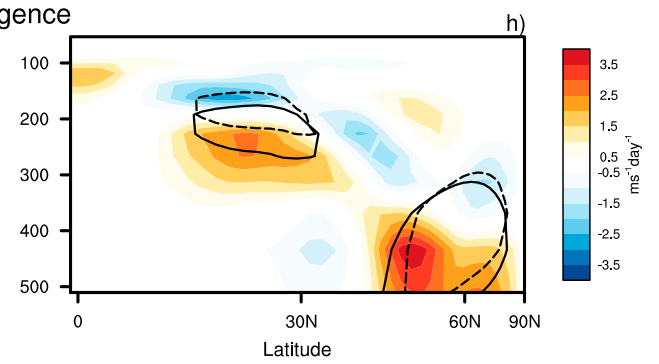

FIG. 3. The long-term mean, zonal-mean clear-sky radiative cooling, mass flux divergence, cloud fraction, and EP flux divergence from the (left) $\mathrm{T}_{\text {ctl }}$ simulation and (right) differences between the $\mathrm{T}_{+4 \mathrm{~K}}$ and $\mathrm{T}_{\mathrm{ctl}}$ simulations. The black contours indicate isopleths from the $\mathrm{T}_{\mathrm{ctl}}$ (solid) and $\mathrm{T}_{+4 \mathrm{~K}}$ (dashed) simulations of (a),(b) $-0.5 \mathrm{~K} \mathrm{day}^{-1}$; (c),(d) the level of largest mass flux divergence; (e),(f) cloud fraction of 0.07 ; and (g),(h) the $-5 \mathrm{~m} \mathrm{~s}^{-1} \mathrm{day}^{-1} \mathrm{EP}$ flux convergence contour. The EP flux divergence is multiplied by the cosine of latitude.

track (i.e., see the isopleths in Fig. 3h). Throughout most of the globe, cloud top and the level of largest negative EP flux divergences both lift by roughly the same distance as the clear-mass flux divergences (contours in Figs. 3f,h). The most notable exception is the large rises in cloud top over very high latitudes.

Figure 4 summarizes the response of the extratropical tropospheric circulation to surface warming in pressure (left panels) and temperature (right panels) coordinates. As noted above, increasing surface temperatures by $4 \mathrm{~K}$ leads to a rising of the $220-\mathrm{K}$ isotherm by $\sim 30-50 \mathrm{hPa}$ at all latitudes (solid lines in all left panels). As the upper troposphere warms, the level of largest mass flux divergences rises (open circles and plus symbols in Fig. 4a). And as the clear-sky mass flux divergences rise, so does cloud top (open circles and 

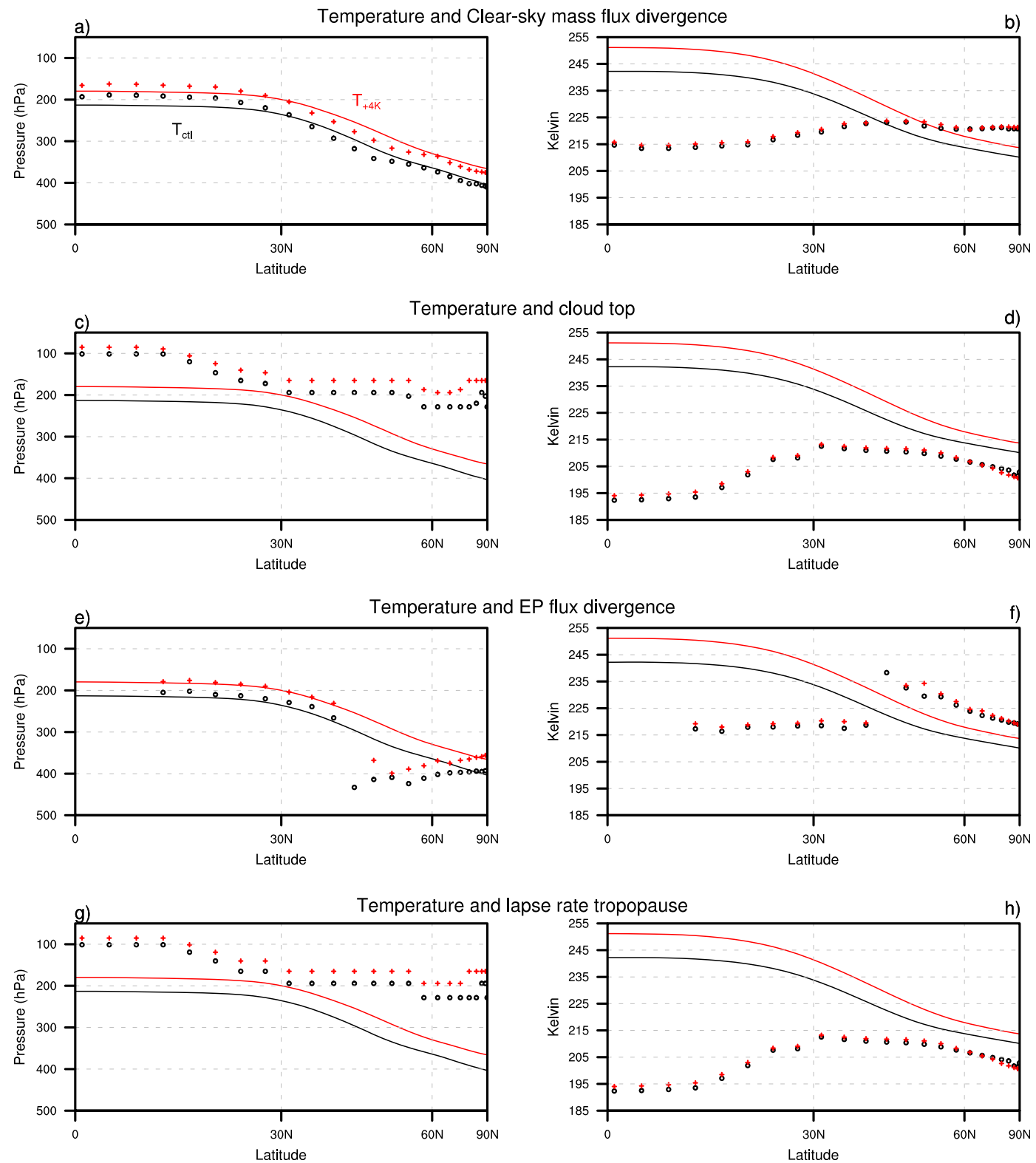

FIG. 4. (left) The long-term mean, zonal-mean $220-\mathrm{K}$ isotherm (solid lines in all panels) overlaid with the mass flux divergence maximum [open circles and plus symbols in (a)], cloud top [open circles and plus symbols in (c)], the level of maximum EP flux convergence [open circles and plus symbols in (e)], and the lapse-rate tropopause [open circles and plus symbols in $(\mathrm{g})]$. Black denotes results from the $\mathrm{T}_{\mathrm{ctl}}$ simulation; red from the $\mathrm{T}_{+4 \mathrm{~K}}$ simulation. (right) As in the left panels, but results are plotted as a function of temperature, and the $220-\mathrm{K}$ isotherm is replaced with the temperature at the $300-\mathrm{hPa}$ level. Cloud-top pressure (temperature) is found as the average pressure (temperature) over the highest three model layers where cloud fraction $>0.01$.

plus symbols in Fig. 4c), the level of largest negative EP flux divergence (open circles and plus symbols in Fig. 4e), and the lapse-rate extratropical tropopause (open circles and plus symbols in Fig. 4g). The temperature of all four fields stays relatively invariant, particularly at extratropical latitudes, despite the fact that the upper troposphere is warming substantially (right column). The relatively weak lifting of the lapse-rate tropopause and cloud top at tropical latitudes (Figs. 4c,g) is consistent with the adjustment of the clear-sky mass fluxes to the increases in static stability as tropical temperatures shift to a warmer moist adiabat (Zelinka and Hartmann 2010). 
b. Experiment sets 2 and 3: Isolating the role of water vapor radiative cooling in the circulation response to surface warming

Experiment sets 2 and 3 explore the effects of water vapor radiative cooling on the circulation response to surface warming in the $\mathrm{T}_{+4 \mathrm{~K}} \mathrm{~W}_{\mathrm{ctl}}$ and $\mathrm{T}_{\mathrm{ctl}} \mathrm{W}_{+4 \mathrm{~K}}$ locking experiments. The left column in Fig. 5 is reproduced from the right panels of Figs. 2 and 3 and recaps the total response to increasing SSTs by $4 \mathrm{~K}$. As discussed in the previous section, the response is characterized by temperature and specific humidity increases in the troposphere (Figs. 5a,d), temperature decreases in the stratosphere (Fig. 5a), enhanced longwave cooling in the upper troposphere (Fig. 5g), and an upward shift of the regions of largest clear-sky mass flux divergence (Fig. 5j), cloud fraction (Fig. 5m), EP flux divergence (Fig. 5p), and the lapse-rate tropopause (Fig. 4g).

The center column in Fig. $5\left(\mathrm{~T}_{+4 \mathrm{~K}} \mathrm{~W}_{\mathrm{ctl}}\right.$ minus $\left.\mathrm{T}_{\mathrm{ctl}} \mathrm{W}_{\mathrm{ctl}}\right)$ shows the response to increasing SSTs by $+4 \mathrm{~K}$ while locking the water vapor concentrations input into the radiation code at their control values. Note that 1 ) the specific humidities seen by the radiation code in both the $\mathrm{T}_{+4 \mathrm{~K}} \mathrm{~W}_{\mathrm{ctl}}$ and $\mathrm{T}_{\mathrm{ctl}} \mathrm{W}_{\mathrm{ctl}}$ simulations are identical and are indicated in Fig. 2c, and 2) the differences between the specific humidities seen by everything but the radiation code in the $\mathrm{T}_{+4 \mathrm{~K}} \mathrm{~W}_{\mathrm{ctl}}$ and $\mathrm{T}_{\mathrm{ctl}} \mathrm{W}_{\mathrm{ctl}}$ simulations are indicated in Fig. 5e. Relative to the total response, fixing water vapor concentrations in the radiation code leads to slightly weaker temperature increases in the troposphere and warming throughout the extratropical stratosphere (cf. Fig. 5a and Fig. 5b). The slightly weaker temperature increases in the $\mathrm{T}_{+4 \mathrm{~K}} \mathrm{~W}_{\text {ctl }}$ simulation are consistent with the facts that 1) temperatures in the $T_{+4 K}$ simulation are forced by increases in both surface temperature and the radiative forcing associated with increasing atmospheric emissivity whereas 2) temperatures in the $T_{+4 K} W_{c t l}$ simulation are forced by increases in surface temperature alone.

Fixing water vapor concentrations in the radiation code strongly constrains the changes in radiative cooling at the tropopause level and thus the lifting of the regions of largest clear-sky radiative cooling (cf. Fig. $5 \mathrm{~g}$ and Fig. 5h). At equilibrium, the changes in clear-sky radiative cooling are predominantly balanced by changes in diabatic heating in cloudy regions. Hence the absence of robust lifting in the isopleths of clear-sky cooling is also reflected in the absence of robust lifting in the clear-sky mass flux divergences (cf. Fig. 5j and Fig. 5k), cloud fraction (cf. Fig. 5m and Fig. 5n), and the depth of extratropical wave driving (cf. Fig. 5p and Fig. 5q). Interestingly, surface warming appears to account for the poleward shift but not the lifting of the region of largest wave diving (cf. Fig. 5p and Fig. 5q). The only region where cloud fraction lifts appreciably is at polar latitudes.

The right column $\left(\mathrm{T}_{\mathrm{ctl}} \mathrm{W}_{+4 \mathrm{~K}}\right.$ minus $\left.\mathrm{T}_{\mathrm{ctl}} \mathrm{W}_{\mathrm{ctl}}\right)$ shows the response to increasing the water vapor concentrations input into the radiation code to their $\mathrm{T}_{+4 \mathrm{~K}}$ values while holding SSTs at their control values. Note that 1) the differences between the specific humidities seen by the radiation code in the $\mathrm{T}_{\mathrm{ctl}} \mathrm{W}_{+4 \mathrm{~K}}$ and $\mathrm{T}_{\mathrm{ctl}} \mathrm{W}_{\mathrm{ctl}}$ simulations are indicated in Fig. 2d, and 2) the differences between the specific humidities seen by everything but the radiation code in the $\mathrm{T}_{\mathrm{ctl}} \mathrm{W}_{+4 \mathrm{~K}}$ and $\mathrm{T}_{\mathrm{ctl}} \mathrm{W}_{\mathrm{ctl}}$ simulations are negligible and are indicated in Fig. 5f. Increasing the amount of water vapor that the radiation code sees has very little effect on the temperature or specific humidity calculated by the dynamical code in the model (Figs. 5c,f). This is because 1) surface temperatures are identical in the $\mathrm{T}_{\mathrm{ctl}} \mathrm{W}_{\mathrm{ctl}}$ and $\mathrm{T}_{\mathrm{ctl}} \mathrm{W}_{+4 \mathrm{~K}}$ experiments, and 2) the free troposphere of the model is in radiative/convective equilibrium, and thus tropospheric temperatures and saturation specific humidities are likewise nearly identical in the two simulations. The primary differences in temperature between the $\mathrm{T}_{\mathrm{ct} 1} \mathrm{~W}_{\mathrm{ctl}}$ and $\mathrm{T}_{\mathrm{ct} 1} \mathrm{~W}_{+4 \mathrm{~K}}$ experiments are found in the model stratosphere, where temperatures decrease slightly (Fig. 5c). The decreases in stratospheric temperatures are consistent with 1) increases in the radiative cooling of the stratosphere because of the in situ increases in water vapor and 2) decreases in the upward radiative flux from the troposphere in regions of the spectrum where the carbon dioxide and water vapor lines overlap.

Holding SSTs fixed between the $\mathrm{T}_{\mathrm{ctl}} \mathrm{W}_{\mathrm{ctl}}$ and $\mathrm{T}_{\mathrm{ctl}} \mathrm{W}_{+4 \mathrm{~K}}$ experiments provides a strong constraint on the vertical structure of atmospheric temperatures. Hence, the changes in atmospheric cooling rates between the $\mathrm{T}_{\mathrm{ctl}^{-}}$ $\mathrm{W}_{\mathrm{ctl}}$ and $\mathrm{T}_{\mathrm{ctl}} \mathrm{W}_{+4 \mathrm{~K}}$ experiments arise primarily from changes in the emissivity (because of the differences in water vapor concentrations) and not changes in temperature (i.e., the Planck function). The changes in midtropospheric clear-sky radiative cooling found in the total response (Fig. $5 \mathrm{~g}$ ) are due primarily to the increases in atmospheric temperatures (Fig. 5h). But the lifting of the profiles of clear-sky radiative cooling is due primarily to the increases in water vapor concentrations input into the radiation code (contours in Fig. 5i). Likewise, the lifting in the profiles of clear-sky mass flux divergence, cloud fraction, and the EP flux divergence are due mostly to the increases in water vapor concentrations input into the radiation code (cf. contours in the bottom three rows of Fig. 5). The largest discrepancies are again found in cloud fraction at polar latitudes, where the increases in clouds are due primarily to the surface warming. 
$\mathrm{T}_{+4 \mathrm{~K}}-\mathrm{T}_{\text {ctl }}$ simulation
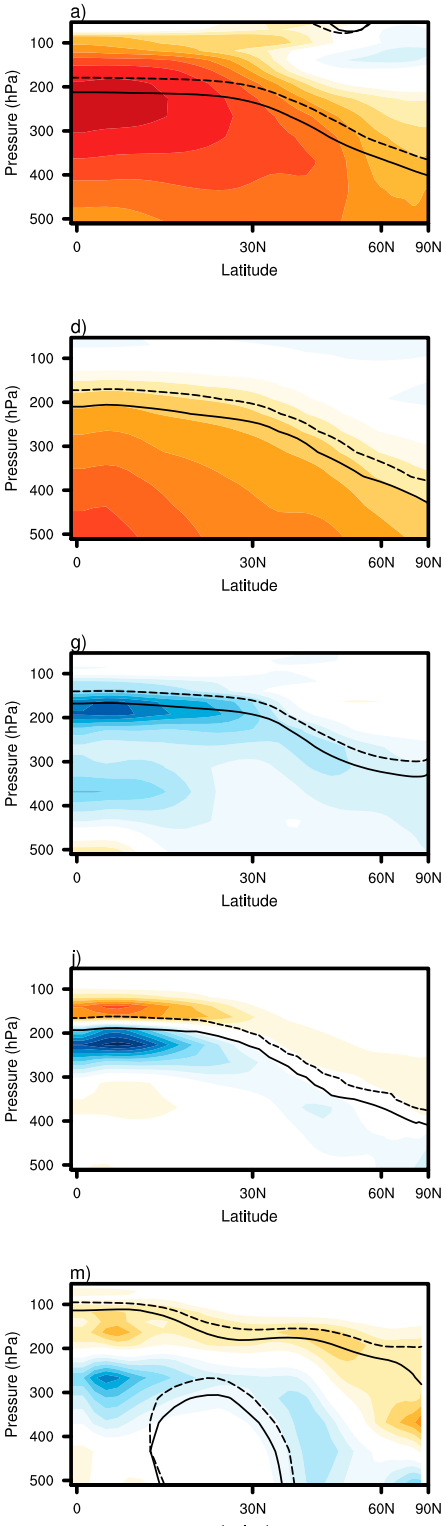

Latitude

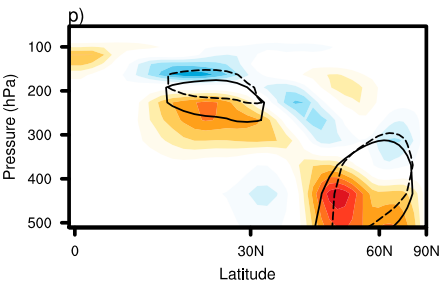

$\mathrm{T}_{+4 \mathrm{~K}} \mathrm{~W}_{\mathrm{ct|}}-\mathrm{T}_{\mathrm{ct|}} \mathrm{W}_{\mathrm{ctl}}$ simulation
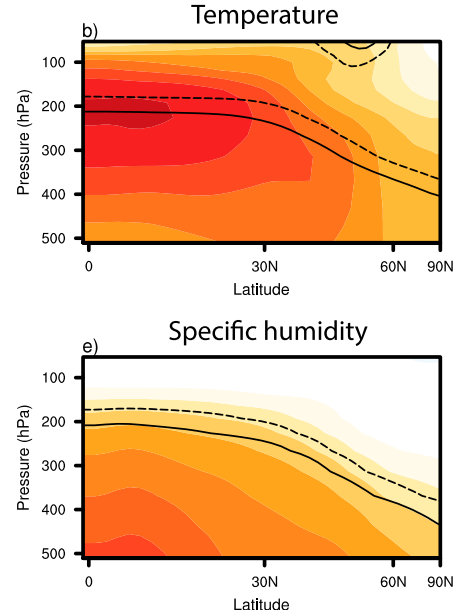

Clear-sky radiative cooling
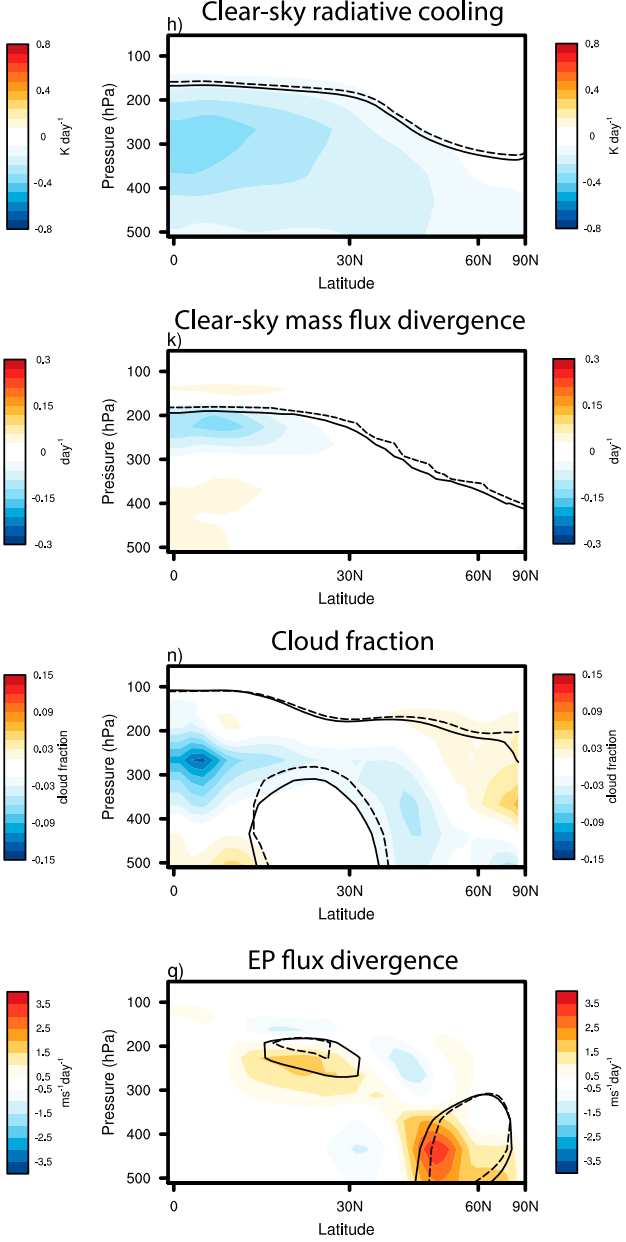

$\mathrm{T}_{\mathrm{ctl}} \mathrm{W}_{+4 \mathrm{~K}}-\mathrm{T}_{\mathrm{ctl}} \mathrm{W}_{\mathrm{ctl}}$ simulation
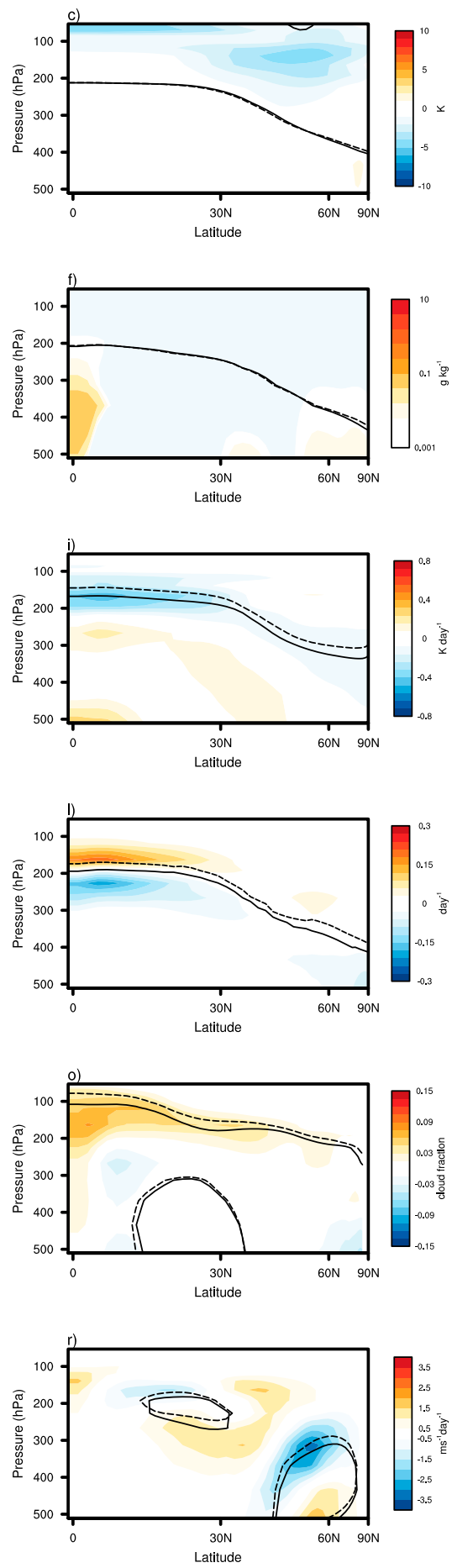

FIG. 5. Rows show the differences between the (left) $\mathrm{T}_{+4 \mathrm{~K}}$ and $\mathrm{T}_{\mathrm{ctl}}$ simulations, (center) $\mathrm{T}_{+4 \mathrm{~K}} \mathrm{~W}_{\mathrm{ctl}}$ and $\mathrm{T}_{\mathrm{ctl}} \mathrm{W}_{\mathrm{ctl}}$ simulations, and (right) $\mathrm{T}_{\mathrm{ctl}} \mathrm{W}_{+4 \mathrm{~K}}$ and $\mathrm{T}_{\mathrm{ctl}} \mathrm{W}_{\mathrm{ctl}}$ simulations. Results for (a)-(c) zonal-mean temperature, (d)-(f) specific humidity, (g)-(i) clear-sky radiative cooling, (j)-(l) clear-sky mass flux divergence, (m)-(o) cloud fraction, and (p)-(r) the EP flux divergence. The black contours indicate the isopleths of $220 \mathrm{~K}$ in (a)-(c), $0.05 \mathrm{~g} \mathrm{~kg}^{-1}$ in (d)-(f), $-0.5 \mathrm{~K} \mathrm{day}^{-1}$ in (g)-(i), the level of largest mass flux divergence in (j)-(l), cloud fraction of 0.07 in (m)-(o), and the $-5 \mathrm{~m} \mathrm{~s}^{-1}$ day $^{-1} \mathrm{EP}$ flux convergence contours in (p)-(r). The contours correspond to results from the $\mathrm{T}_{\mathrm{ctl}} \mathrm{W}_{\mathrm{ctl}}$ simulation (solid in all columns), the $\mathrm{T}_{+4 \mathrm{~K}}$ simulation (dashed in left column), the $\mathrm{T}_{+4 \mathrm{~K}} \mathrm{~W}_{\mathrm{ctl}}$ simulation (dashed in center column), and the $\mathrm{T}_{\mathrm{ctl}} \mathrm{W}_{+4 \mathrm{~K}}$ simulation (dashed in right column). The EP flux divergence is multiplied by the cosine of latitude. Light blue shading in (f) indicates specific humidities between -0.001 and $0 \mathrm{~g} \mathrm{~kg}^{-1}$. The results in the left panel are reproduced from the right columns in Figs. 2 and 3. 

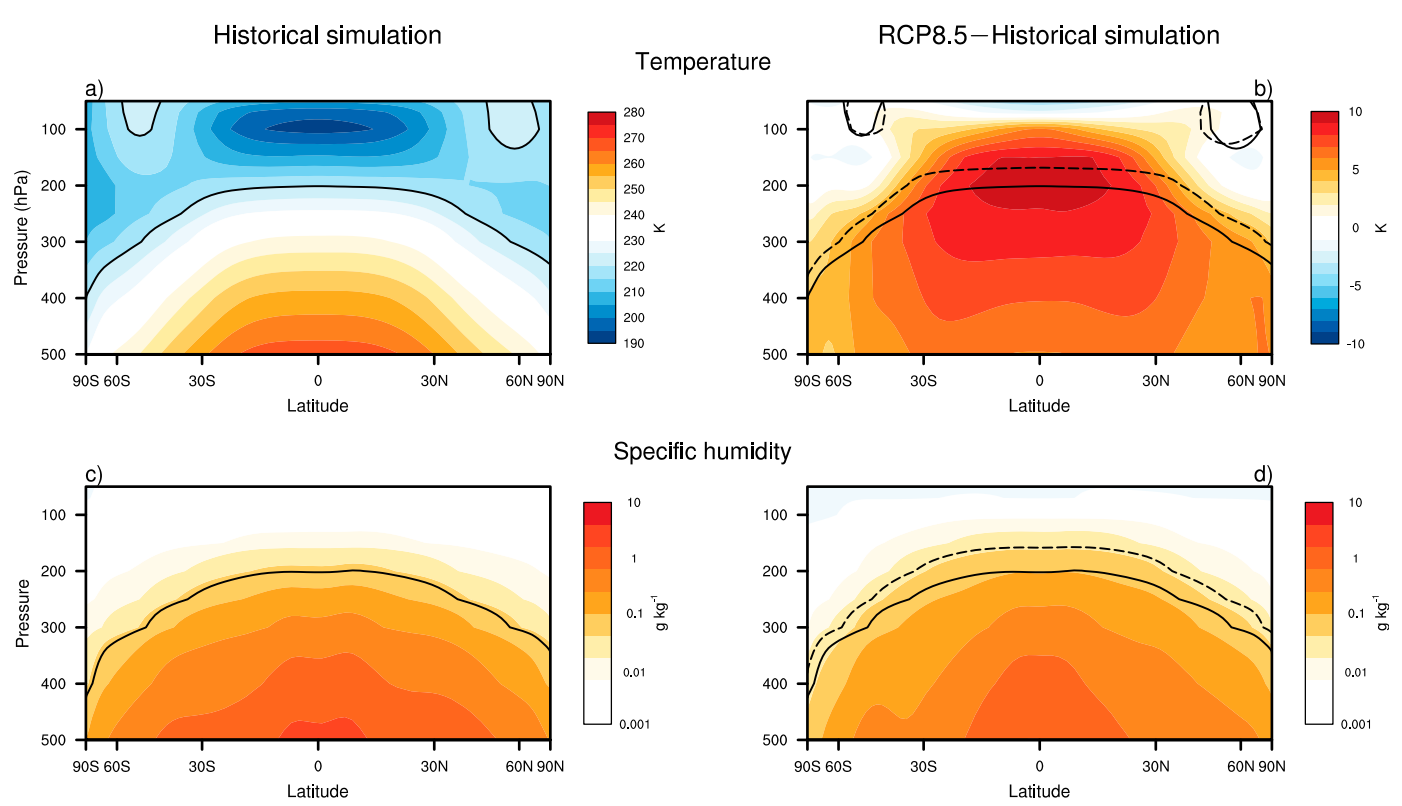

FIG. 6. As in Fig. 2, but for temperature and specific humidity from the (a),(c) historical simulation and (b),(d) differences between the RCP8.5 and historical simulations. The historical simulation results are averaged over 19792005; the RCP8.5 simulation results are averaged between 2070 and 2099. The solid black contours indicate the (left) 220-K and (right) $0.05 \mathrm{~g} \mathrm{~kg}^{-1}$ isopleths from the historical (solid) and RCP8.5 (dashed) simulations. Output is from the CMIP5 simulations run on the IPSL-CM5A-LR climate model.

The key results from experiment sets 2 and 3 are that 1) locking the amount of water vapor in the radiation code as SSTs increase leads to a suppression of the lifting of the extratropical tropopause, while 2) increasing only the amount of water vapor in the radiation code leads to a notable lifting of the extratropical tropopause.

\section{c. Other experiments}

We conducted a series of additional fixed-SST aquaplanet experiments that test whether 1) the absence of stratospheric ozone in the $\mathrm{T}_{\mathrm{ctl}}$ and $\mathrm{T}_{+4 \mathrm{~K}}$ simulations leads to even smaller changes in tropopause temperature than those indicated in Figs. 2-4 (i.e., ozone contributes to the static stability and thus the amplitude of the clear-sky subsidence in the lower stratosphere; Harrop and Hartmann 2012), 2) the results are robust to larger surface warming (increasing SSTs by $8 \mathrm{~K}$ ), and 3 ) the results are robust to increases in the meridional temperature gradient and thus the potential energy available for conversion to eddy kinetic energy. The results of the additional experiments do not fundamentally change the basic conclusions from this section and are summarized in the appendix.

\section{Implications for climate change}

The results in the previous section suggest that the depth of mixing by extratropical dynamics is constrained by the amplitude of clear-sky radiative cooling by water vapor. The results imply that the extratropical tropopause should remain at roughly the same temperature under climate change. In this section, we explore to what extent this occurs in a climate-change simulation run on an AOGCM forced with RCP8.5 scenario emissions.

Figure 6 shows meridional profiles of atmospheric temperature and specific humidity from the historical simulation (left panels) and the differences between the RCP8.5 and historical simulations (right panels). The differences in atmospheric temperature and specific humidity bear close resemblance to the differences between the control and $+4 \mathrm{~K}$ aquaplanet simulations (cf. Fig. 2 and Fig. 6). Increasing atmospheric greenhouse gases leads to warming throughout the troposphere that peaks in the tropics around $200 \mathrm{hPa}$ and widespread increases in specific humidity that peak in the lower tropical troposphere. As is the case in the aquaplanet simulations, the $220-\mathrm{K}$ isotherm and $0.5 \mathrm{~g} \mathrm{~kg}^{-1}$ isopleth lift by $\sim 50 \mathrm{hPa}$ across the globe (black contours).

Figure 7 shows attendant results for cloud fraction and the EP flux divergence. As is the case in the aquaplanet GCM response to surface warming, the AOGCM response to RCP8.5 scenario emissions includes a lifting of both cloud fraction and the EP flux divergences throughout the troposphere, as evidenced by the vertical dipoles in the trends in both fields (Figs. 7b,d; shading) and the highlighted isopleths of cloud fraction and EP 

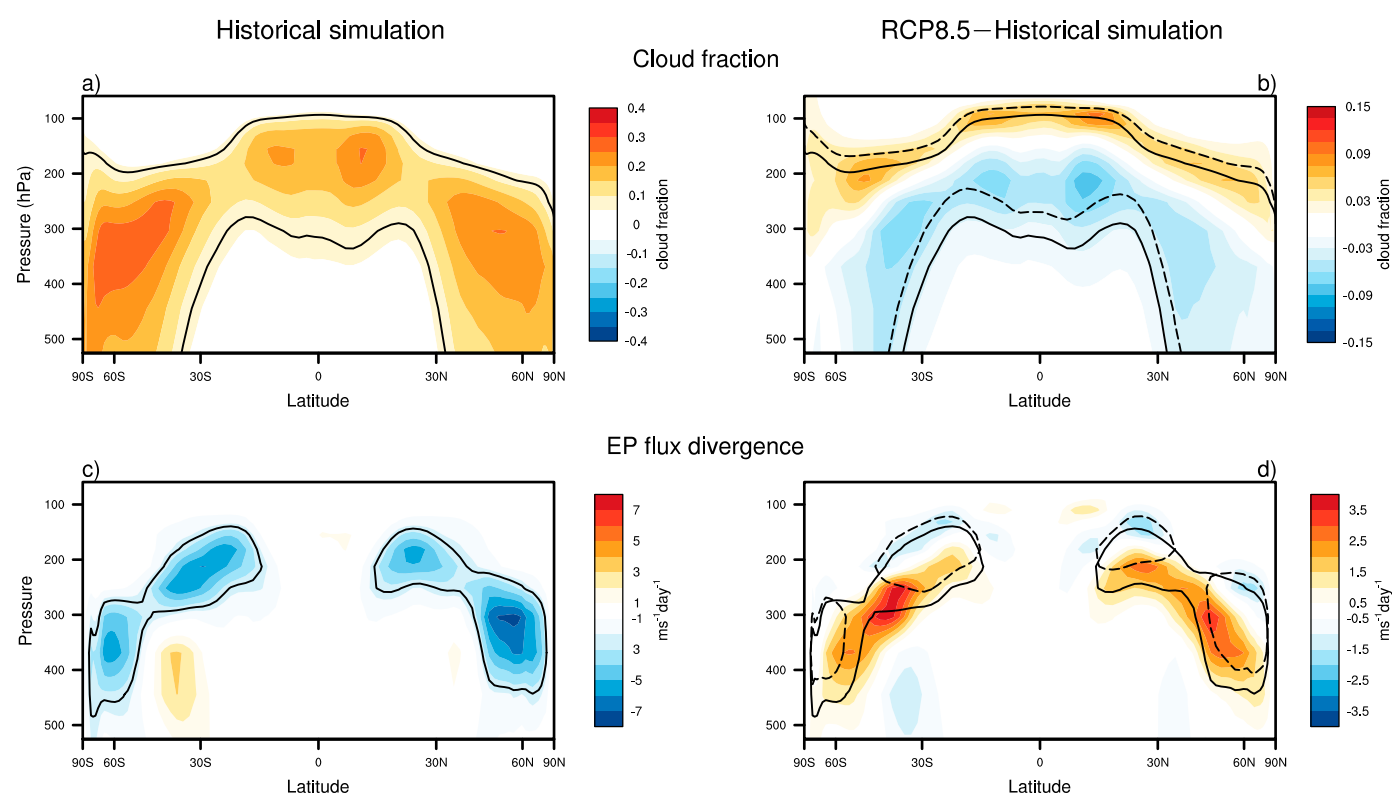

FIG. 7. As Figs. 3e-h, but for cloud fraction and the EP flux divergence from the (left) historical simulation and (right) differences between the RCP8.5 and historical simulation. The black contours indicate where (a),(b) cloud fraction equals 0.07 and (c),(d) the EP flux divergence equals $-2.5 \mathrm{~m} \mathrm{~s}^{-1} \mathrm{day}^{-1}$ from the historical (solid) and RCP8.5 (dashed) simulations. Output is from the CMIP5 simulations run on the IPSL-CM5A-LR climate model. The EP flux divergence is multiplied by the cosine of latitude.

flux convergence (Figs. 7b,d; contours). As shown in Fig. 8, the cloud-top pressure, the level of largest negative EP flux divergence, and the lapse-rate tropopause all rise by $\sim 50 \mathrm{hPa}$ across the globe in the RCP8.5 scenario (Fig. 8; left column open circles and plus symbols), consistent with the upward shift of the tropospheric circulation identified in previous analyses of climate change (Mitchell and Ingram 1992; Santer et al. 2003; Lorenz and DeWeaver 2007; Singh and O'Gorman 2012). The key result in Fig. 8 is that the temperature of cloud-top pressure, largest EP flux convergence, and the lapse-rate tropopause change much less than the temperature on upper-tropospheric isobars (Fig. 8; right column).

\section{Discussion}

The Clausius-Clapeyron relation leads to a range of "robust" constraints on the atmospheric circulation response to climate change. These include decreases in the convective mass flux (Betts 1998; Held and Soden 2006), decreases in the meridional sensible heat transport at midlatitudes (Manabe and Wetherald 1975; Held and Soden 2006), increases in the horizontal moisture flux (Mitchell et al. 1987; Held and Soden 2006), and nearly invariant longwave radiant emissions from tropical anvil clouds (Hartmann and Larson 2002; Zelinka and Hartmann 2010).
In a recent study, we argued that the ClausiusClapeyron relation also leads to a robust constraint on the temperature of the extratropical tropopause and thus the depth of mixing by large-scale extratropical eddies (Thompson et al. 2017). The argument is predicated on the same basic physics that govern anvil cloud temperature in the tropics. That is, the temperature of the tropopause and thus depth of tropospheric mixing should be limited by the amplitude of diabatic sinking motion - and thus radiative cooling-in clear-sky regions not only in the tropics (Hartmann and Larson 2002) but in the extratropics as well. Since clear-sky cooling rates are constrained by water vapor concentrations, diabatic mixing must decrease rapidly at temperatures where the saturation vapor pressure becomes very small.

The Clausius-Clapeyron relation may thus be viewed as providing a "thermodynamic constraint" on tropopause temperature and height that acts in conjunction with the "radiative and dynamical constraints" described in Held (1982). The radiative constraint defines the tropopause as the lowest level at which the atmosphere is in radiative equilibrium. Hence the tropopause height can be calculated from radiative-convective equilibrium given the tropospheric lapse rate (Held 1982). One form of the dynamical constraint requires that the tropospheric lapse rate be neutral to both convective and-in the midlatitudes-baroclinic instability (Held 1982; Zurita-Gotor and Lindzen 2007). The thermodynamic 

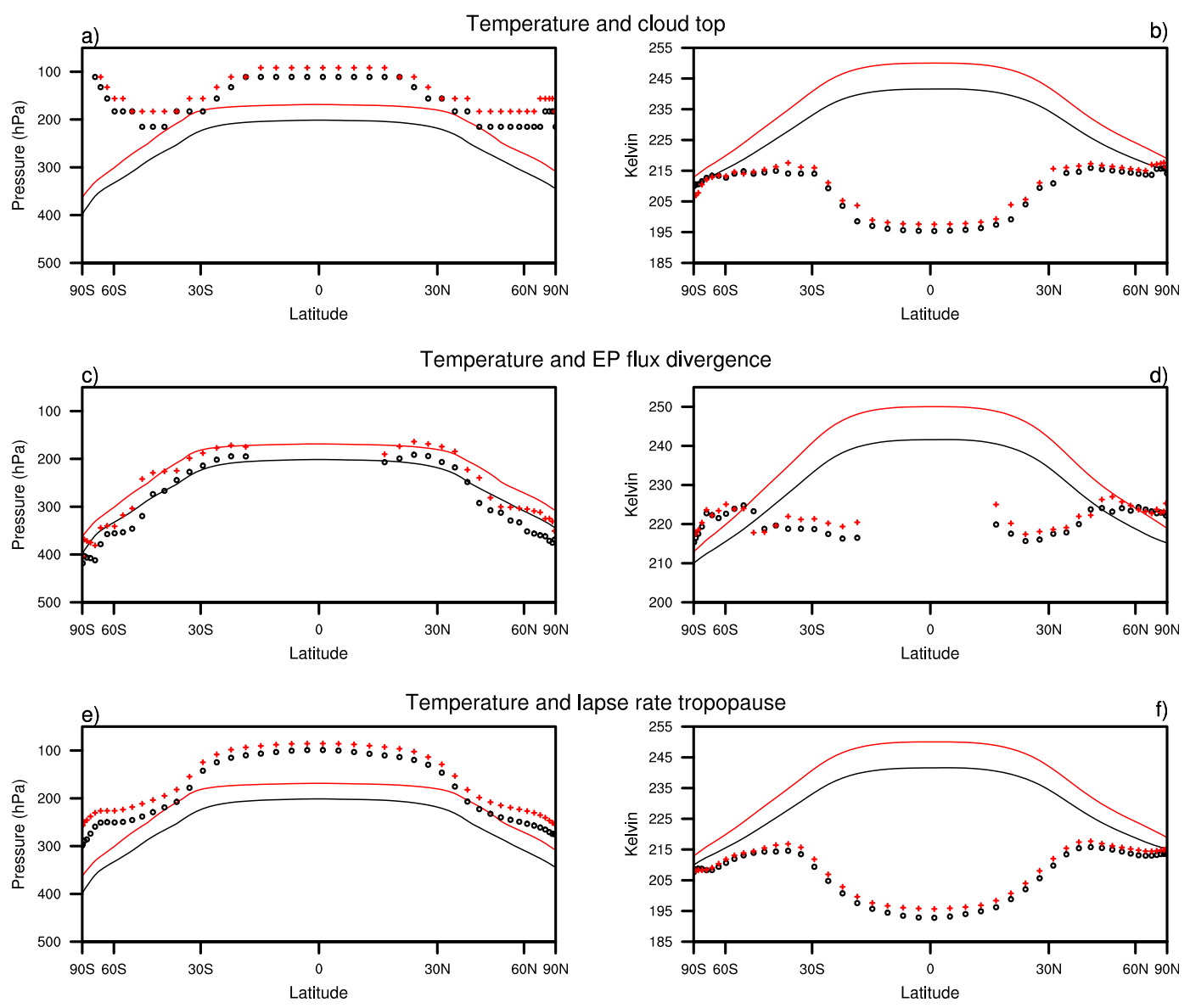

FIG. 8. As in the bottom three rows of Fig. 4, but for results from the historical (black) and RCP8.5 (red) simulations. Output is from the CMIP5 simulations run on the IPSL-CM5A-LR climate model.

constraint-as defined here-argues that the extratropical tropopause corresponds to the level where water vapor concentrations (and thus clear-sky radiative cooling) decrease rapidly with height in accordance with the Clausius-Clapeyron relation. The thermodynamic constraint is potentially important since it implies that extratropical cloud top, the level of largest extratropical wave driving, and the extratropical tropopause should all remain at roughly the same temperature-and thus shift upward-under climate change. Here we explored the robustness and implications of the constraint in numerical simulations run on an aquaplanet GCM and an AOGCM.

We explored three primary sets of simulations run on the aquaplanet GCM: 1) A simulation forced with increases in SSTs, 2) a locking simulation forced by increasing SSTs while holding fixed the amount of water vapor input into the radiation code, and 3) a locking simulation forced by increasing the amount of water vapor input into the radiation code while holding fixed
SSTs. We also explored output from a coupled AOGCM forced with the RCP8.5 emissions scenario. The aquaplanet model response to increasing SSTs and the AOGCM response to increasing greenhouse gases both indicate lifting of the tropospheric circulation under global warming that spans the globe. In the extratropics, the lifting of the circulation is marked by rises in the levels of 1) the largest clear-sky vertical mass flux divergences, 2) cloud top, 3) the largest extratropical wave driving (as given by the EP flux divergence), and 4) the lapse-rate tropopause. Importantly, the temperature of all four levels remains roughly invariant even as the surface warms. The aquaplanet locking experiments further indicate that 1) locking the amount of water vapor in the radiation code suppresses the lifting of the extratropical tropopause and the deepening of the extratropical tropospheric circulation that occurs in response to surface warming, while 2) increasing only the amount of water vapor in the radiation code leads to a lifting of the extratropical tropopause and a deepening 
of the extratropical tropospheric circulation, even when surface temperatures are held fixed.

Together, the numerical simulations suggest that 1) longwave radiative cooling-and thus water vapor concentrations-provide a strong constraint on the depth of mixing by large-scale extratropical dynamics, and 2) the temperature of the extratropical tropopause-and thus of extratropical high clouds - remains largely invariant under global warming.

The results shown here have several implications for our understanding of the climate system. They suggest that radiative cooling by water vapor plays a central role in governing the vertical structure and amplitude of extratropical dynamics. They suggest that the extratropical tropopause should remain at roughly the same temperature under climate change. They provide a physical explanation for why the extratropical tropospheric circulation should lift in climatechange simulations (Mitchell and Ingram 1992; Santer et al. 2003; Lorenz and DeWeaver 2007; Singh and O'Gorman 2012). And they provide a physical explanation for why the positive climate feedbacks associated with high clouds extend throughout much of the globe (Wetherald and Manabe 1988; Zelinka et al. 2012, 2013).

Acknowledgments. We thank Thomas Birner and three anonymous reviewers for helpful comments on the manuscript. D.W.J.T. is funded by NSF Climate and Large-Scale Dynamics (AGS-1343080 and AGS-1547003). P.C. is supported by an Imperial College Research Fellowship. Y.L. is funded by NSF Climate and Large-Scale Dynamics (AGS-1547003) and NASA JPL (1439268). This work used the ARCHER U.K. National Supercomputing Service (http://www.archer.ac.uk).

\section{APPENDIX}

\section{Additional Experiments}

\section{a. Increasing SSTs by $4 \mathrm{~K}$ with no ozone}

Harrop and Hartmann (2012) argue that cloud-top temperatures increase slightly in global-warming simulations since 1) high clouds penetrate levels where ozone heating contributes to the vertical temperature gradient, and 2) the increases in clear-sky static stability lead to a slight downward shift in the level of largest clear-sky mass fluxes. If the inclusion of stratospheric ozone contributes to increases in cloud-top temperature in global-warming simulations, then it follows that cloudtop temperature should be almost perfectly invariant in simulations run without ozone. We redid the $\mathrm{T}_{+4 \mathrm{~K}}$ and
$\mathrm{T}_{\mathrm{ctl}}$ simulations after setting the concentrations of all radiatively active gases other than water vapor to effectively zero (i.e., $\mathrm{T}_{+4 \mathrm{~K}, \mathrm{wv}}$ and $\mathrm{T}_{\mathrm{ctl}, \mathrm{wv}}$ ). The experiments are similar to the "H2Oonly" experiments in Harrop and Hartmann (2012), except that their runs are performed on a cloud-resolving model and ours are performed in a GCM.

The heights of the model lapse-rate tropopause and the largest clear-sky mass flux divergences are largely unchanged across the globe between the $\mathrm{T}_{\mathrm{ctl}, \mathrm{wv}}$ and $\mathrm{T}_{\mathrm{ctl}}$ simulations, consistent with our hypothesis that the global tropopause is governed primarily by the vertical structure of water vapor radiative cooling (not shown). However, removing ozone and carbon dioxide also leads to clouds that extend to temperatures as cold as $190 \mathrm{~K}$ and thus well above the $50 \mathrm{hPa}$ level in the tropics in the $\mathrm{T}_{\mathrm{ctl}, \mathrm{wv}}$ simulation (see also Harrop and Hartmann 2012, Fig. 5 therein). The extension of clouds to nearly $190 \mathrm{~K}$ is consistent with the decreases in stratospheric static stability and temperature that accompany the removal of ozone (Harrop and Hartmann 2012). Consistent with Harrop and Hartmann (2012, Fig. 6 therein), cloud-top temperatures are effectively invariant between the $T_{+4 K, w v}$ and $\mathrm{T}_{\mathrm{ctl}, \mathrm{wv}}$ simulations, even though they extend to higher levels in both simulations.

\section{b. Increasing SSTs by $8 \mathrm{~K}$}

Simulations run in an identical manner to $\mathrm{T}_{+4 \mathrm{~K}}$ but for SST raised by $8 \mathrm{~K}$ yield very similar conclusions to those derived from the $\mathrm{T}_{+4 \mathrm{~K}}$ simulation. The isopleths of upper-tropospheric clear-sky radiative cooling, cloud-top pressure, the level of largest EP flux divergences, and the lapse-rate tropopause all lift by roughly twice as much as they do in the $\mathrm{T}_{+4 \mathrm{~K}}$ simulation. Cloudtop temperature remains nearly invariant at extratropical latitudes but increases slightly in the tropics, consistent with the accompanying increases in clearsky static stability. The increases in static stability mean that a smaller clear-sky mass flux is required to balance a given diabatic heating and arise from 1) the shift in tropospheric temperatures to warmer moist adiabats (Zelinka and Hartmann 2010) and 2) the extension of cloud top to altitudes where ozone heating contributes to the vertical temperature gradient (Harrop and Hartmann 2012).

\section{c. Increasing the meridional temperature gradient by 2 and $4 K$}

The default SST distribution has two parameters for the maximum and minimum SST. In the Qobs distribution used in the $\mathrm{T}_{\mathrm{ctl}}$ simulation, these are $27^{\circ}$ and $0^{\circ} \mathrm{C}$ 
[see Neale and Hoskins (2000) for details of the distribution]. We ran two experiments where the maximum and minimum SST were changed to $28^{\circ}$ and $-1{ }^{\circ} \mathrm{C}$ and $29^{\circ}$ and $-2^{\circ} \mathrm{C}$, thus increasing the equator-to-pole temperature gradient by 2 and $4 \mathrm{~K}$, respectively. Increasing the meridional temperature gradient provides additional potential energy for developing baroclinic waves and scales with the meridional slope and height of the extratropical tropopause (e.g., Stone 1978; Schneider 2004). It also increases the strength of the westerly flow in the upper troposphere/lower stratosphere, thus allowing a larger spectrum of zonal wavenumbers to propagate vertically into the model stratosphere. Any resulting strengthening of the model Brewer-Dobson circulation would be expected to lead to a lifting of the tropopause in the tropics and depression of the tropopause at high latitudes (e.g., Thuburn and Craig 2000; Birner 2010; Haqq-Misra et al. 2011) butaccording to our hypothesis-little change in tropopause temperatures.

The most pronounced differences in the extratropical circulation when the meridional temperature gradient is increased include a lifting of extratropical clouds to slightly lower pressures and less EP flux convergence in the extratropical upper troposphere (the reasons for the weakening of the wave driving are unclear but are not the focus of this study). The isopleths of extratropical clear-sky radiative cooling, cloud-top pressure, largest mass flux divergence, largest EP flux convergence, and the lapse-rate tropopause all remain at roughly the same temperature across the globe when the meridional temperature gradient is increased by both 2 and $4 \mathrm{~K}$.

\section{REFERENCES}

Betts, A. K., 1998: Climate-convection feedbacks: Some further issues. Climatic Change, 39, 35-38, https://doi.org/10.1023/ A:1005323805826.

Birner, T., 2010: Residual circulation and tropopause structure. J. Atmos. Sci., 67, 2582-2600, https://doi.org/10.1175/ 2010JAS3287.1.

Collins, W. D., and Coauthors, 2006: The formulation and atmospheric simulation of the Community Atmosphere Model Version 3 (CAM3). J. Climate, 19, 2144-2161, https://doi.org/ 10.1175/JCLI3760.1.

Dee, D. P., and Coauthors, 2011: The ERA-Interim reanalysis: Configuration and performance of the data assimilation system. Quart. J. Roy. Meteor. Soc., 137, 553-597, https://doi.org/ 10.1002/qj.828.

Dufresne, J.-L., and Coauthors, 2013: Climate change projections using the IPSL-CM5 Earth system model: From CMIP3 to CMIP5. Climate Dyn., 40, 2123-2165, https://doi.org/10.1007/ s00382-012-1636-1.

Edmon, H. J., Jr., B. J. Hoskins, and M. E. McIntyre, 1980: EliassenPalm cross sections for the troposphere. J. Atmos. Sci., 37,
2600-2616, https://doi.org/10.1175/1520-0469(1980)037<2600: EPCSFT $>2.0 . C O ; 2$; Corrigendum, 38, 1115, https://doi.org/ 10.1175/1520-0469(1981)038<1115: >2.0.CO;2.

Haqq-Misra, J., S. Lee, and D. M. W. Frierson, 2011: Tropopause structure and the role of eddies. J. Atmos. Sci., 68, 2930-2944, https://doi.org/10.1175/JAS-D-11-087.1.

Harrop, B. E., and D. L. Hartmann, 2012: Testing the role of radiation in determining tropical cloud top temperature. J. Climate, 25, 5731-5747, https://doi.org/10.1175/ JCLI-D-11-00445.1.

Hartmann, D. L., and K. Larson, 2002: An important constraint on tropical cloud-climate feedback. Geophys. Res. Lett., 29, 1951, https://doi.org/10.1029/2002GL015835.

_- J. R. Holton, and Q. Fu, 2001: The heat balance of the tropical tropopause, cirrus, and stratospheric dehydration. Geophys. Res. Lett., 28, 1969-1972, https://doi.org/10.1029/ 2000 GL012833.

Held, I. M., 1982: On the height of the tropopause and the static stability of the troposphere. J. Atmos. Sci., 39, 412-417, https:// doi.org/10.1175/1520-0469(1982)039<0412:OTHOTT>2.0.CO;2.

_ , and B. J. Soden, 2006: Robust responses of the hydrological cycle to global warming. J. Climate, 19, 5686-5699, https:// doi.org/10.1175/JCLI3990.1.

Hourdin, F., and Coauthors, 2006: The LMDZ4 general circulation model: Climate performance and sensitivity to parameterized physics with emphasis on tropical convection. Climate Dyn., 27, 787-813, https://doi.org/10.1007/s00382-006-0158-0.

Ingram, W., 2010: A very simple model for the water vapour feedback on climate change. Quart. J. Roy. Meteor. Soc., 136, 30-40, https://doi.org/10.1002/qj.546.

Lorenz, D. J., and E. T. DeWeaver, 2007: Tropopause height and zonal wind response to global warming in the IPCC scenario integrations. J. Geophys. Res., 112, D10119, https://doi.org/ 10.1029/2006JD008087.

Manabe, S., and R. F. Strickler, 1964: Thermal equilibrium of the atmosphere with a convective adjustment. J. Atmos. Sci., 21, 361-385, https://doi.org/10.1175/1520-0469(1964)021<0361: TEOTAW $>2.0 . \mathrm{CO} ; 2$.

-_ and R. T. Wetherald, 1975: The effect of doubling $\mathrm{CO}_{2}$ concentration on the climate of the general circulation model. J. Atmos. Sci., 32, 3-15, https://doi.org/10.1175/ 1520-0469(1975)032<0003:TEODTC >2.0.CO;2.

Mitchell, J. F. B., and W. J. Ingram, 1992: Carbon dioxide and climate: Mechanisms of changes in cloud. J. Climate, 5, 5-21, https://doi.org/10.1175/1520-0442(1992)005<0005: $\mathrm{CDACMO}>2.0 . \mathrm{CO} ; 2$.

— C. A. Wilson, and W. M. Cunnington, 1987: $\mathrm{On} \mathrm{CO}_{2}$ climate sensitivity and model dependence of result. Quart. J. Roy. Met. Soc., 113, 293-322, https://doi.org/10.1002/qj.49711347517.

Neale, R. B., and B. J. Hoskins, 2000: A standard test for AGCMs including their physical parametrizations: I: The proposal. Atmos. Sci. Lett., 1, 101-107, https://doi.org/10.1006/asle.2000.0022.

Santer, B. D., and Coauthors, 2003: Contributions of anthropogenic and natural forcing to recent tropopause height changes. Science, 301, 479-483, https://doi.org/10.1126/science.1084123.

Schneider, T., 2004: The tropopause and the thermal stratification in the extratropics of a dry atmosphere. J. Atmos. Sci., 61 , 1317-1340, https://doi.org/10.1175/1520-0469(2004)061<1317: TTATTS $>2.0$.CO;2.

Simpson, G. C., 1928: Some studies in terrestrial radiation. Mem. Roy. Meteor. Soc., 2, 69-95.

Singh, M. S., and P. A. O'Gorman, 2012: Upward shift of the atmospheric general circulation under global warming: Theory 
and simulations. J. Climate, 25, 8259-8276, https://doi.org/ 10.1175/JCLI-D-11-00699.1.

Stone, P. H., 1978: Baroclinic adjustment. J. Atmos. Sci., 35, 561-571, https://doi.org/10.1175/1520-0469(1978)035<0561:BA $>$ 2.0.CO;2.

Thompson, D. W. J., S. Bony, and Y. Li, 2017: Thermodynamic constraint on the depth of the global tropospheric circulation. Proc. Nat. Acad. Sci. USA, 114, 8181-8186, https://doi.org/ 10.1073/pnas.1620493114.

Thuburn, J., and G. C. Craig, 2000: Stratospheric influence on tropopause height: The radiative constraint. J. Atmos. Sci. 57, 17-28, https://doi.org/10.1175/1520-0469(2000)057<0017: SIOTHT $>2.0 . \mathrm{CO} ; 2$.

Wetherald, R. T., and S. Manabe, 1988: Cloud feedback processes in a general circulation model. J. Atmos. Sci., 45, 1397-1415, https://doi.org/10.1175/1520-0469(1988)045<1397: CFPIAG $>2.0 . \mathrm{CO} ; 2$.
Zelinka, M. D., and D. L. Hartmann, 2010: Why is longwave cloud feedback positive? J. Geophys. Res., 115, D16117, https:// doi.org/10.1029/2010JD013817.

, S. A. Klein, and D. L. Hartmann, 2012: Computing and partitioning cloud feedbacks using cloud property histograms. Part II: Attribution to changes in cloud amount, altitude, and optical depth. J. Climate, 25, 3736-3754, https://doi.org/10.1175/ JCLI-D-11-00249.1.

K. E. Taylor, T. Andrews, M. J. Webb, J. M. Gregory, and P. M. Forster, 2013: Contributions of different cloud types to feedbacks and rapid adjustments in CMIP5. J. Climate, 26, 5007-5027, https://doi.org/10.1175/JCLI-D-12-00555.1.

Zurita-Gotor, P., and R. S. Lindzen, 2007: Theories of baroclinic adjustment and eddy equilibration. The Global Circulation of the Atmosphere: Phenomena, Theory, Challenges, T. Schneider and A. H. Sobel, Eds., Princeton University Press, $22-46$. 